Bangladesh J. Bot. 44(2): 201-207, 2015 (June)

\title{
GENETIC DIVERGENCE IN COMMERCIAL CUCUMBER (CUCUMIS SATIVUS L.) GENOTYPES
}

\section{Rokib Hasan, Mohammed Kamal Hossain*, Nazmul Alam, Abul Bashar, Saidul Islam AND MoHammad Jahangir Alam TARAFder}

\author{
Department of Botany, Jahangirnagar University, Savar, Dhaka-1342, Bangladesh
}

Key words: Cucumber, Path analysis, Genetic divergence, Cluster analysis, D² statistics, Biplot.

\begin{abstract}
Genetic diversity in commercial cucumber genotypes was estimated based on 13 characters. Path analysis revealed that fruits/plant (0.701) and fruit weight (0.379) had maximum positive direct effect on yield. Seven cucumber genotypes were grouped into three different clusters. The highest inter-cluster distance (4.078) was observed between cluster I and II whereas lowest inter-cluster distance (1.011) was observed between the clusters I and III. Cluster II showed highest mean for length of main vine, nodes/plant, primary branches/plant, days to 1st male flowering, length of internodes/plant, fruits/plant and yield/plant whereas cluster III produced highest mean for leaf length, leaf breadth, fruit length, fruit diameter and fruit weight. Cluster II and III contributed 53.85 and 38.46\%, respectively towards divergence.
\end{abstract}

\section{Introduction}

Cucumber (Cucumis sativus L.) commonly known as 'Shosha' is one of the most important vegetables belonging to family Cucurbitaceae consumed as a salad (Arankumar et al. 2011). Cucumber cultivation goes back to at least 3000 years in India and 2000 years in China (Robinson and Decker-Walters 1997). The crop is grown throughout the world and is the fourth most important vegetable crop after tomato, cabbage, and onion (Tatlioglu 1993). It has tremendous economic and dietic importance. It is a good source of water, minerals, carbohydrates, protein, lipid, ion and vitamin in human diet (Rashid 1999). Demand of cucumber as cooling vegetables is increasing day by day. Everyone is fond of eating this vegetable as raw for refreshment, especially as salad with fast food (Reshma 2011).

In Bangladesh, the yield of cucumber is very low due to lack of high yielding varieties. The total production of cucumber in Bangladesh was about 48,000 metric tons from 19,000 acres during 2010-2011 (BBS 2011). So, intensive research efforts are needed in several areas, particularly, selection of superior genotypes. For an effective breeding program, information concerning the extent and nature of genetic diversity within a crop species is essential. Better knowledge on genetic diversity or genetic similarity could help to sustain long term selection gain in plants (Chowdhury et al. 2002). Very few research work relating to diversity of cucumber have been conducted in Bangladesh (Hossain et al. 2010). In view of these facts, the present investigation was undertaken to evaluate the potentiality of existing market germplasm of cucumber through the studies of genetic divergence and path analysis.

\section{Materials and Methods}

The investigation was conducted during February - May, 2013 at Botanical Garden of Jahangirnagar University, Savar, Dhaka, Bangladesh. The experimental site was at 23० 52' 27.76" north latitude, $90^{\circ} 16^{\prime} 5.16^{\prime \prime}$ east longitudes, with an altitude of $13.716 \mathrm{~m}$ above the sea level.

*Author for correspondence: <kamal_juniv@yahoo.com>. 
Adequate soil fertility was ensured by applying additional quantities of FYM- N-P- K- @ 25-30$50-80 \mathrm{~kg} / \mathrm{ha}$, respectively. The pit unit was $4 \times 4$ feet maintaining a plant spacing of $1 \times 1$ feet. A distance of two feet in the form of drain was maintained between the block and between the plots within a block. The genotypes named Shila, Myabi, Green top, Shufola-1, Green master, Shosa baromasi, Super-1 were used as experimental materials. Data were collected from 3 randomly selected plants basis for length of main vine $(\mathrm{cm})$, no. of nodes/plant, leaf length $(\mathrm{cm})$, leaf breadth $(\mathrm{cm})$, no. of primary branch, days to 1st male flowering, days to 1st female flowering, length of inter node $(\mathrm{cm})$, fruit length $(\mathrm{cm})$, fruit diameter $(\mathrm{cm})$, fruit weight $(\mathrm{gm})$, no. of fruits/plant, yield/plant (gm). Path analysis has been done using programming software R-3.1.1. Mean data of each character was subjected to multivariate analysis viz. principal coordinate analysis (PCO), principal component analysis (PCA), cluster analysis, and canonical variate analysis using GENSTAT 5.13 (Mahalanobis 1936, Digby et al. 1989).

\section{Results and Discussion}

The interrelationships among different traits along direct and indirect effects were worked out using path coefficient analysis in respect to yield. Path coefficient analysis revealed the causes and effects of chain relationships of different yield contributing characters with yield. The estimates of direct effects of these characters on yield based on genotypic correlation are presented in Fig. 1. Path coefficient analysis showed that number of fruits/plant had maximum positive direct effect (0.701) on yield/plant (Fig. 1). Similar result was obtained by Hossain et al. (2010), Rao et al. (2004), Arunkumar et al. (2011) and Golabadi et al. (2013). Length of main vine (0.045), nodes/plant (0.006), leaf length (0.063), fruit length (0.020), fruit diameter $(0.066)$ and fruit weight (0.379) also showed positive direct effect upon yield. The direct effect of above mentioned characters were negligible except number of fruits/plant and fruit weight as in comparison to correlation with yield. It is suggested that selection of these two characters would give better response for yield improvement.

After computing $\mathrm{D}^{2}$ values for all the possible pairs, 7 genotypes were grouped into 3 clusters, which indicated a considerable genetic diversity (Table 1). The clustering pattern of different genotypes did not follow their geographical distribution and was fairly at random. This suggested that the materials of same origin into different clusters were an indication of broad genetic base of the genotypes. Prasad et al. (2001) reported the similar result when they studied 60 inbreed lines of cucumber.

Based on PCA score I, II and III a three dimensional scattered diagram was developed where the positions of 7 genotypes were apparently distributed into three groups (Fig. 2). Inter-genotypic distance $\left(\mathrm{D}^{2}\right)$ was obtained from principal coordinate analysis for all possible combinations among genotypes. The highest inter-genotype distance (2.6164) was observed between Sufoa-1 and Mayabi followed by (2.0299) and (1.7773) distance observed between Sufoa-1 and Shila and between Sufoa-1 and Green top, respectively (Fig. 3). The lowest distance (0.3337) was observed between Shila and Green top followed by the distance (0.44) was observed between the Green master and Super-1. The highest inter genotypic distance indicated the presence of dissimilarity among the concerned genotypes of cucumber.

Maximum numbers of genotypes were accommodated in clusters I and III comprising 3 genotypes while cluster II containing single genotype (Table 1). Intra-cluster distance revealed that, cluster I showed maximum intra-cluster distance (0.165) followed by cluster III (0.142) but cluster II (0.00) showed no intra-cluster distance due to solitary genotype. Based on distance between clusters, the inter cluster $\mathrm{D}^{2}$ values also ranged from 1.011 to 4.708 (Table 2). The intercluster distances were larger than the intra-cluster distances which indicated wider genetic 
diversity among the genotypes of different groups. Clusters I and II were strikingly diverse from rest of the clusters, the divergence between these two clusters was high as evident from their high

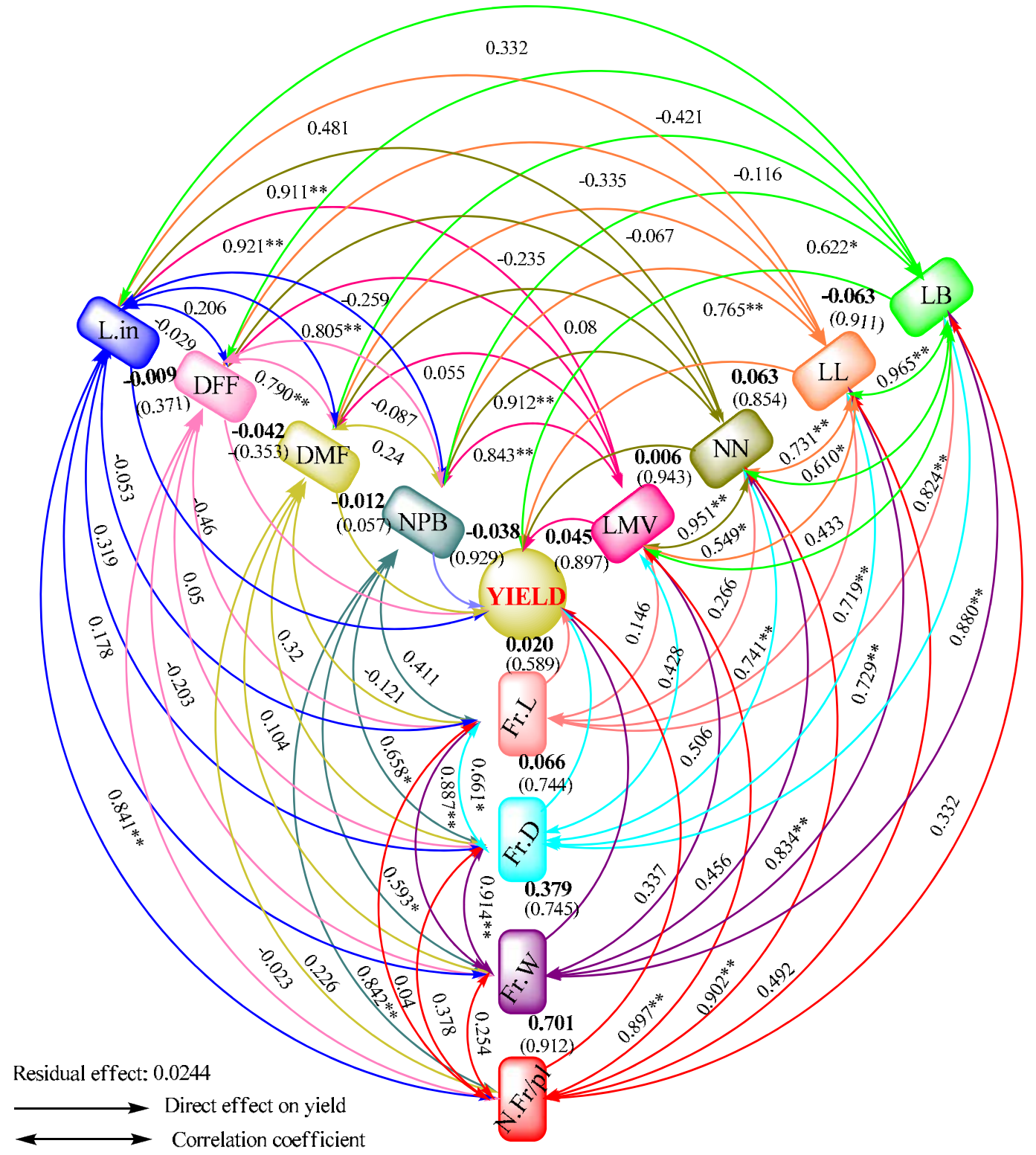

( ) Total correlation to yield

Fig. 1. Path diagram of different yield contributing characters on yield per plant at genotypic level. LMV = Length of main vine, NN $=$ No. of nodes, $L L=$ Leaf length, $L B=$ Leaf breadth, NPB $=$ No. of primary branch, $\mathrm{DMF}=$ Days to 1 st male flowering, $\mathrm{DFF}=$ Days to 1 st female flowering, $\mathrm{L}$. In $=$ Length of internodes, Fr. L = Fruit length, Fr. $\mathrm{D}=$ Fruit diameter, Fr. $\mathrm{W}=$ Fruit weight, $\mathrm{N} . \mathrm{Fr} / \mathrm{Pl}=$ No. of fruits/plant. $* *=$ Significant at $1 \%$ level of probability and $*=$ Significant at $5 \%$ level of probability. 
inter cluster $\mathrm{D}^{2}$ value (4.078). Therefore, the genotypes belonging to these clusters were genetically more divergent which suggested intercrossing the genotypes from these two clusters may generate wider variability and is expected to throw high yielding transgressive segregants in improvement programme. The minimum inter-cluster $\mathrm{D}^{2}$ value (1.011) observed between clusters I and III indicated that genotypes of these two clusters were more or less genetically same. Similar finding was reported by Rao et al. (2003).

Table 1. Distribution of different cucumber genotypes.

\begin{tabular}{ccl}
\hline Cluster & No. of genotypes & Name of the genotype \\
\hline I & 3 & Shila, Mayabi, Green top \\
II & 1 & Shufola-1 \\
III & 3 & Green master, Shosa baromasi, Super-1 \\
\hline
\end{tabular}

Table 2. Average intra (bold) and inter-cluster distance $\left(D^{2}\right)$ for cucumber genotypes.

\begin{tabular}{cccc}
\hline Cluster & I & II & III \\
\hline I & $\mathbf{0 . 1 6 5}$ & & \\
II & 4.708 & $\mathbf{0 . 0 0 0}$ & $\mathbf{0 . 1 4 2}$ \\
III & 1.011 & 1.941 & \\
\hline
\end{tabular}

Character wise mean were estimated for all the genotypes spread over three clusters (Table 3). Among the 13 characters the following characters such as; length of main vine, nodes/plant, primary branches/plant, fruit weight, fruits/plant and yield/plant were considered as superior characters based on maximum range of variability observed in different cluster mean (Table 3). Cluster I showed lowest mean value for almost all the characters except one character (Days to 1st female flowering) indicating selection of parental lines from this cluster for future hybrid cucumber breeding programme is ineffective.

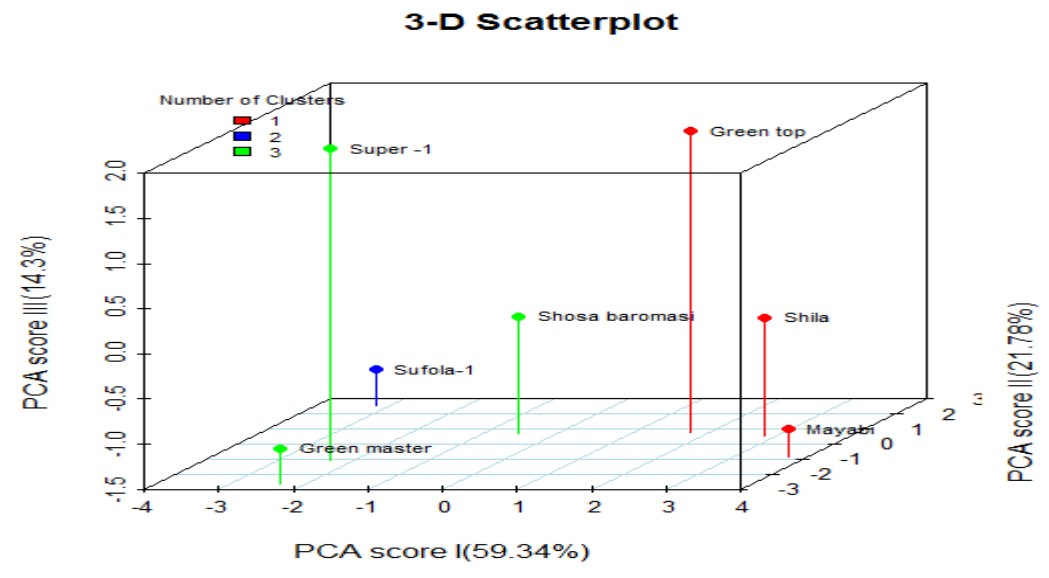

Fig. 2. Three dimensional scattered diagram based on three PCA scores showing the distribution of different genotypes. 


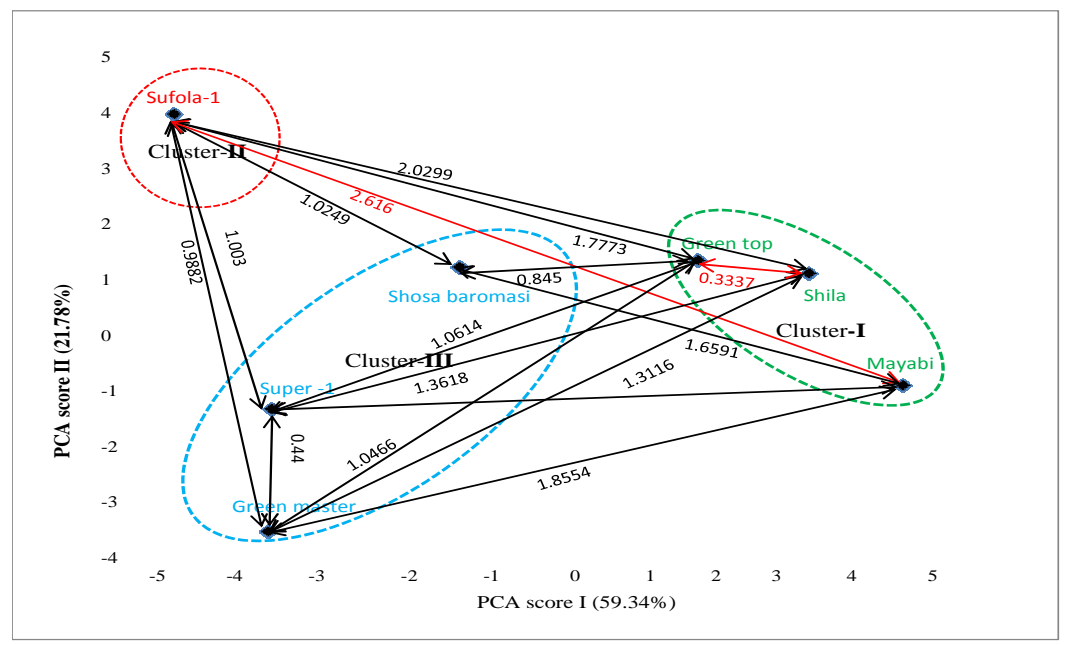

Fig. 3. Inter-genotypic distance $\left(\mathrm{D}^{2}\right)$ of different genotypes based on principal coordinate analysis.

Cluster II contained highest mean value for 7 characters and cluster III showed highest mean value for 5 characters, hence, they contributed 53.85 and 38.46\% (Table 3) respectively, towards divergence that refers possession of superior characters in these clusters in respect of yield which also indicated the presence of most promising genotypes available in these clusters. Considering the magnitude of genetic distance, character contribution towards divergence and cluster mean for different characters performance, the genotypes Sufola-1, Green master, Shosa baromasi and Super-1 could be selected effectively for further breeding programme (Table 4).

Table 3. Cluster mean for various characters of cucumber genotypes.

\begin{tabular}{llccc}
\hline Characters & Cluster I & Cluster II & Cluster III & $\begin{array}{c}\text { Contribution towards } \\
\text { divergence (\%) }\end{array}$ \\
\hline Length of main vine (cm) & 287.9 & $918.6^{*}$ & 490.6 & 0 \\
Nodes/plant & 24.5 & $66.4^{*}$ & 46.4 & 0 \\
Leaf length (cm) & 12.3 & 14.1 & $15.1^{*}$ & 0 \\
Leaf breadth (cm) & 13.7 & 15.7 & $18.2^{*}$ & 0 \\
Primary branch & 2.5 & $7.1^{*}$ & 5.3 & 0 \\
Days to 1st male flowering & 37 & $37.3^{*}$ & 36.8 & 0 \\
Days to 1st female flowering & $48.4^{*}$ & 46.7 & 46.8 & 0 \\
Length of inter-node (cm) & 10.9 & $14.4^{*}$ & 12.1 & 0 \\
Fruit length (cm) & 18.9 & 19.1 & $21^{*}$ & 0 \\
Fruit diameter (cm) & 16.9 & 18.3 & $19.1 *$ & 14.29 \\
Fruit weight (g) & 281.9 & 310.3 & $362.5^{*}$ & 0 \\
Fruit /plant & 5.1 & $11.6^{*}$ & 7.3 & 47.61 \\
Yield/plant (g) & 1453.3 & $3585^{*}$ & 2653.3 & 38.10 \\
\hline Contribution (\%) & 7.69 & 53.85 & 38.46 & 100 \\
\hline
\end{tabular}

*= Highest mean value. 
Table 4. Finally selected cucumber genotypes for important traits.

\begin{tabular}{lllll}
\hline Sl. No. & Selection traits & Genotypes & Cluster & Mean value \\
\hline 1 & Length of main vine $(\mathrm{cm})$ & Sufola-1 & II & 918.6 \\
2 & Primary branches/plant & Sufola-1 & II & 7.1 \\
3 & Fruit weight (g) & Green master, Shosa baromasi, Super-1 & III & 362.5 \\
4 & Fruit diameter (cm) & Green master, Shosa baromasi, Super-1 & III & 19.1 \\
5 & Fruits/plant & Sufola-1 & II & 11.6 \\
6 & Yield/plant (g) & Sufola-1 & II & 3585 \\
\hline
\end{tabular}

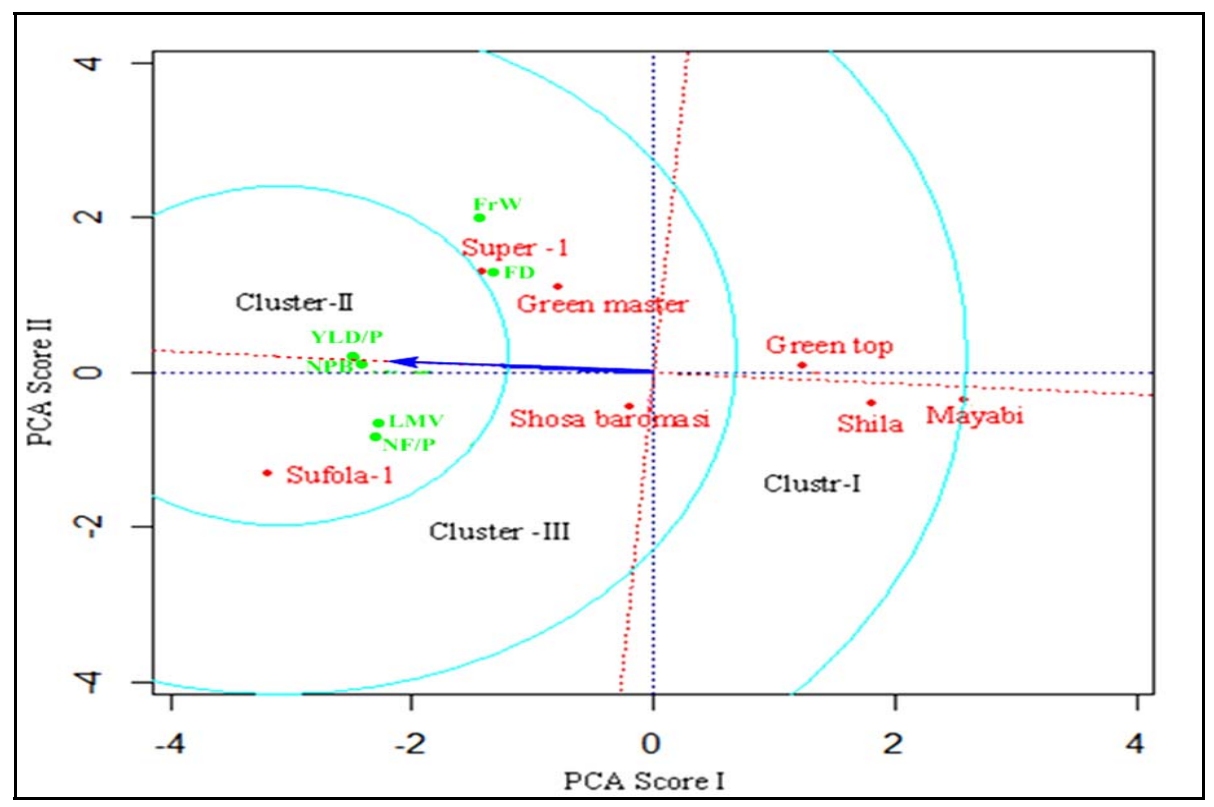

Fig. 4. Ranking of cucumber genotypes having important characters.

LMV = Length of main vine, NPB = No. of primary branch, NF/Pl = No. of fruits/plant, Fr.W = Fruit weight, $\mathrm{FD}=$ Fruit diameter, YLD/P $=$ Yield/plant.

Genotypes were ranked using biplot method (Fig. 4). A genotype is ideal if it is located at the center of the concentric circles and closer to the line passing through the biplot origin called the indicator of superiority (blue line) which is defined by the average PCA scores I and II of the selected characters. Therefore, Sufola-1 was more reliable followed by Super-1, Green master and Shosa baromasi. These genotypes can be developed as parental line for further breeding programme.

\section{Acknowledgement}

The authors are thankful to AKM Mahmudul Huque, Ph.D. student of Plant Molecular Genetics Lab., School of Life Sciences and Biotechnology, Nok-Ji (Green) Campus, Korea University, Seoul 136-701 for his valuable suggestions during the experiment and preparation of the manuscript. 


\section{References}

Arunkumar KH, Patil MG, Hanchinamani CN, Goud IS, Hiremath SV 2011. Genetic relationship of growth and development traits with fruit yield in $F_{2}$ population of BGDL $\times$ Hot season of cucumber (Cucumis sativus L.). Karnataka J. Agric. Sci. 24: 497-500.

BBS 2011. Yearbook of Agricultural Statistics. Bangladesh Bureau of Statistics. Statistics Division. Ministry of Planning. Dhaka, Bangladesh. p. 136.

Chowdhury MA, Vandenberg V and Warkentin T 2002. Cultivar identification and genetic relationship among selected breeding lines and cultivars in chick pea (Cicer arietinum L). Euphytica 127(3): 317-325.

Digby P, Galway N and Lane P 1989. Genstat 5: A Second Course. Oxford Sci. Publication, Oxford. pp. 103-108.

Golabadi M, Eghtedary AR and Golkar P 2013. Determining relationships between different horticultural traits in (Cucumis sativus L.) genotypes with multivariate analysis. SABRAO J. Breed. Genet. 45(3): 447-457.

Hossain F, Rabbani MG, Hakim MA, Amanullah ASM and Ahsanullah ASM 2010. Study on variability character association and yield performance of Cucumber (Cucumis sativus L.). Bangladesh Res. Pub. J. 4(3): 297-311.

Mahalanobis PC 1936. On the generalized distance in statistics. Proceedings of National Institute of Science, India 2: 49-55.

Prasad VSRK, Jain BP, Verma SPP and Ganguly DK 2001. Diversity pattern and choice of parents for hybridization in slicing cucumber (Cucumis sativus L.). J. Res. Birsa. Agril. Univ. 13(1): 33-39.

Rao ES, Verma VK and Munshi AD 2003. Breeding potential of cucumber (Cucumis sativus L.) genotypes using $\mathrm{D}^{2}$ analysis. Ind. J. Hort. 60(1): 53-58.

Rao ES, Munshi AD and Verma VK 2004. Genetic association and interrelationship of yield and its components in cucumber (Cucumis sativus L.). Ind. J. Hort. 61(4): 315-318.

Rashid MM 1999. Sabgi Biggan ( in Bangla). Rashid Publishing House, Dhaka. p. 303.

Reshma, Alam N, Hossain MK 2011. Variability and correlation studies in short cucumber (Cucumis sativus L.). Jahangirnagar University J. Biol. Sci. 23(2): 33-37.

Robinson RW and Decker Walters DS 1997. Cucubits. University press, Cambridge London, UK. pp. 14-115.

Tatlioglu T 1993. Cucumber (Cucumis sativus L.). pp. 197-233. In: Genetic Improvement of Vegetable Crops. Kalloo, G. and B.O. Beorgh (eds.). Pergamon Press, Oxford. 